\title{
Effects of nucleus basalis magnocellularis stimulation on a socially transmitted food preference and c-Fos expression
}

\author{
Núria Boix-Trelis, Anna Vale-Martínez, ${ }^{1}$ Gemma Guillazo-Blanch, \\ David Costa-Miserachs, and Margarita Martí-Nicolovius \\ Departament de Psicobiologia i Metodologia de les Ciències de la Salut Institut de Neurociències, Universitat Autònoma \\ de Barcelona, Barcelona 08193, Spain
}

\begin{abstract}
Experiment 1 examined the effects of electrical stimulation of nucleus basalis magnocellularis (NBM) on a relational odor-association task-the social transmission of food preference (STFP). Rats were stimulated unilaterally in the NBM for $20 \mathrm{~min}(100 \mu \mathrm{A}, 1 \mathrm{~Hz})$ immediately before the social training. They were tested on their ability to remember preference for the trained food either immediately or following a 24-h delay. Stimulation of NBM improved retention regardless of delay, and additional behavioral measures (social interaction, motor activity, or exploration) did not account for such effects. Experiment 2 investigated brain regions activated after NBM electrical stimulation by examining the induction of c-Fos. This treatment led to bilateral increased c-Fos expression in prefrontal regions, such as orbitofrontal, prelimbic, and infralimbic cortices, and some hippocampal subregions (dorsal CA and ventral dentate gyrus). In contrast, no differences between groups in c-Fos expression were found in basolateral amygdala, dorsal dentate gyrus, ventral CA, or ventral subiculum. Present findings indicate that pretraining NBM electrical stimulation facilitates the acquisition of STFP, supporting a role of NBM in the early stages of memory formation, and suggest that the treatment might cause such effects by inducing neural changes, related to transcription factors such as c-Fos, in the prefrontal cortex or the hippocampal formation.
\end{abstract}

The nucleus basalis magnocellularis (NBM) of the basal forebrain provides the major cholinergic innervation to the prefrontal, frontal, and parietal areas of the cerebral cortex (Johnston et al. 1979; Lehmann et al. 1980; Wenk et al. 1980; Mesulam et al. 1983; Woolf et al. 1983; Casamenti et al. 1986; Kurosawa et al. 1989) and also sends extensive projections to the amygdala (Mesulam et al. 1983). NBM neurons serve an important function in the modulation of cognitive processes (Everitt and Robbins 1997; Wenk 1997; McGaughy et al. 2002; Gold 2003; Sarter et al. 2003). Numerous studies propose a well-established role of the NBM, especially its cholinergic cells, in certain attentional processes (Chiba et al. 1995; Baxter and Chiba 1999; Baxter et al. 1999; Gill et al. 2000; Himmelheber et al. 2001; Sarter et al. 2001; McGaughy et al. 2002; Lehmann et al. 2003). There is also growing evidence that implicates the cholinergic NBM in cognitive functions that may be categorized as mnemonic (Berger-Sweeney et al. 2000; Linster et al. 2001; Vale-Martinez et al. 2002; Bailey et al. 2003; Butt et al. 2003; Chudasama et al. 2004; Ridley et al. 2005; Winters and Bussey 2005), supporting findings from initial studies that showed NBM contribution to learning and memory. However, early experiments predominantly evaluated the effects of nonspecific lesions in the NBM, which damaged cholinergic and noncholinergic neurons, on spatial tasks (e.g., Wenk et al. 1989; Langlais et al. 1993).

The involvement of NBM in learning and memory may possibly be linked to its role in the modulation of cortical activity (Detari 2000; Duque et al. 2000; Semba 2000) and certain forms of synaptic plasticity (Rasmusson 2000; Verdier and Dykes 2001; Weinberger 2003). This relationship has been traditionally inves-

\footnotetext{
${ }^{1}$ Corresponding author.

E-mail Anna.Vale@uab.es; fax 34-93-5812001.

Article published online before print. Article and publication are at http:// www.learnmem.org/cgi/doi/10.1101/lm.305306.
}

tigated by lesion studies; cholinergic NBM lesions diminished dendritic morphology in the cortex (Works et al. 2004) and disrupted reorganization of cortical sensorimotor representations, thus impairing motor learning (Conner et al. 2003). Nevertheless, in recent years, electrical stimulation of NBM has become progressively more helpful as a method for investigating the functional involvement of this nucleus in learning processes (Zhang et al. 2005; Miasnikov et al. 2006). Stimulation of the NBM produces a widespread activation of the cortex (Casamenti et al. 1986; Buzsaki et al. 1988; Kurosawa et al. 1989; Metherate and Ashe 1991; Metherate et al. 1992; Jimenez-Capdeville et al. 1997; Rasmusson 2000; McLin III et al. 2002) that correlates with enhanced sensory processing (Bringmann and Klingberg 1990; Hars et al. 1993; Edeline et al. 1994; Mercado et al. 2001). Furthermore, electrophysiological studies have shown that NBM electrical stimulation enhances learning-induced receptive field plasticity in the cortex, which may be regarded as a basis for the formation of specific memory traces (Bakin and Weinberger 1996; Bjordahl et al. 1998; Kilgard and Merzenich 1998; Dimyan and Weinberger 1999; Kilgard et al. 2001; Miasnikov et al. 2001; Weinberger 2003, 2004; Pandya et al. 2005; Miasnikov et al. 2006).

Nevertheless, greater knowledge of both behavioral effects on learning tasks and molecular consequences of NBM electrical stimulation is needed. Some of the few studies that have addressed the first issue have reported that electrical stimulation of the NBM paired with a tone induces the formation of specific associative memory, measured by changes in heart rate and respiration (McLin III et al. 2002) that can develop rapidly (Miasnikov et al. 2006). Pretraining NBM stimulation has also been shown to modulate performance in the acquisition of an implicit learning task, facilitating two-way active avoidance conditioning (Montero-Pastor et al. 2004). As for molecular changes induced by NBM stimulation, there is only one earlier study that has 
characterized the induction of $c$-fos mRNA following NBM stimulation, albeit in response to a unilateral kainate injection into the NBM (Wood and de Belleroche 1991). The immediate early gene c-fos is believed to be an indicator of neural activation involved in changes in cellular functioning linked to plasticity (Herrera and Robertson 1996; Herdegen and Leah 1998). The cellular networks underlying the effects of NBM electrical stimulation on behavior and plasticity could therefore be appraised by examining the expression of the c-Fos protein.

For further insight into the effects of NBM stimulation, we carried out two experiments. Experiment 1 evaluated the effects of NBM electrical stimulation on social transmission of food preference (STFP) and Experiment 2 assessed c-Fos expression to identify brain regions activated by NBM stimulation treatment. The STFP is based on a task developed by Galef Jr. (Galef Jr. and Wigmore 1983) that includes social interaction between "demonstrator" (conspecific that has recently eaten odorized food) and "observer" animals. During this interaction, the observers form an association between the food odor and a constituent of the demonstrator's breath—carbon disulfide (Galef Jr. et al.
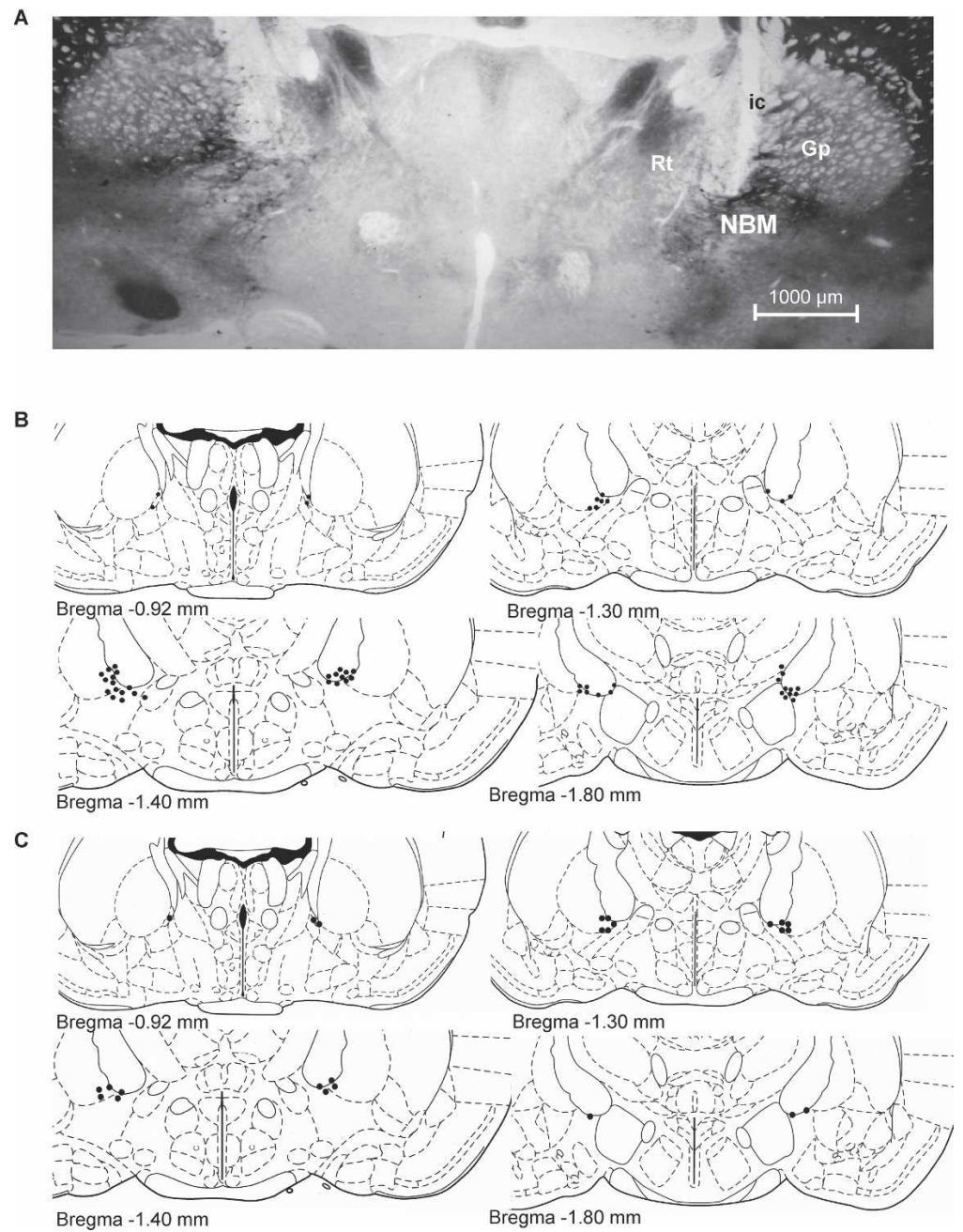

Figure 1. (A) Photomicrograph of AChE staining at the level of the NBM area (AP, 0.92 $1.30 \mathrm{~mm}$ posterior to bregma) showing the electrode track of a representative subject. $(B, C)$ Electrode tip placements (black dots) for stimulated and control rats throughout the rostral-caudal extent of the NBM (from 0.92 to $1.80 \mathrm{~mm}$ posterior to bregma) in experiments $1(B)$ and 2 (C). Reprinted with permission from Elsevier ( $)$ 1997, Paxinos and Watson 1997; ic, internal capsule; Gp, globus pallidus; NBM, nucleus basalis magnocellularis; Rt, reticular thalamic nucleus.
1988) —and in a subsequent test they will choose to eat more of the food previously eaten by the demonstrator in preference to another food (Galef Jr. et al. 1985). STFP is thus a social memory paradigm that involves a natural odor-odor association, requiring rats to use information obtained in one episode of social from the original learning. This flexible memory expression is a key feature of relational memory (Bunsey and Eichenbaum 1995; Eichenbaum 1999; Alvarez et al. 2001). The integrity of the hippocampus and related areas is necessary for expression of the (Winocur 1990; Bunsey and Eichenbaum 1995; Kogan et al. 1997; Mayeux-Portas et al. 2000; Rampon et al. 2000; Alvarez et al. 2001; Winocur et al. 2001; Clark et al. 2002; Roberts and Shapiro 2002; Brightwell et al. 2005; Countryman et al. 2005a; Ross and Eichenbaum 2006). selective cholinergic NBM damage (Berger-Sweeney et al. 2000; Vale-Martinez et al. 2002), suggesting a critical role of NBM neurons in acquisition and early consolidation of the task. Some of the NBM terminal fields in the neocortex are also involved in STFP acquisition, such as frontal (Winocur and Moscovitch 1999) and orbitofrontal (OFC) cortices (Ross et al. 2005). In Experiment 2, we studied the expression of the c-Fos protein to determine whether a single session of NBM electrical stimulation induces molecular changes in brain regions involved in STFP, such as hippocampal formation (CA, dentate gyrus, and subiculum) or OFC. Additional regions, such as other prefrontal regions (prelimbic [PL] and infralimbic [IL] cortices) and the basolateral complex of the amygdala (BLA), were analyzed as they are important targets of projections arising from NBM (Mesulam et al. 1983) and show changes in c-Fos expression after olfactory associative learning (Tronel and Sara 2002).

In short, in the present study, we investigated (1) the effects of pretraining NBM electrical stimulation on preference for the trained food and other variables involved in a STFP task, at two retention delays (immediate and $24 \mathrm{~h}$ ) in separate groups, and (2) the effects of the same stimulation treatment on the activation of different cortical and subcortical regions.

\section{Results}

\section{Experiment 1}

\section{Histology}

At the end of the experiment, all observer rats were subjected to histological verification of electrode placements. For the final sample we only considered rats with their electrode tips in the NBM within the area demarcated by caudal globus pallidus and adjacent internal capsula (Fig. 1A). Specifically, the electrodes were located along different brain coordinates from 0.92 to $1.80 \mathrm{~mm}$ posterior to bregma (Fig. 1B) according to the stereotaxic atlas (Paxinos and Watson 1997). Control $(n=4)$ and stimulated $(n=20)$ subjects with the electrode unintentionally implanted outside NBM (internal capsule, lateral globus pallidus, or reticular thalamic nucleus) were not included in the main analyses, although the performance of rats stimulated outside the NBM was compared with that of NBM-stimulated and controls in a supple- 


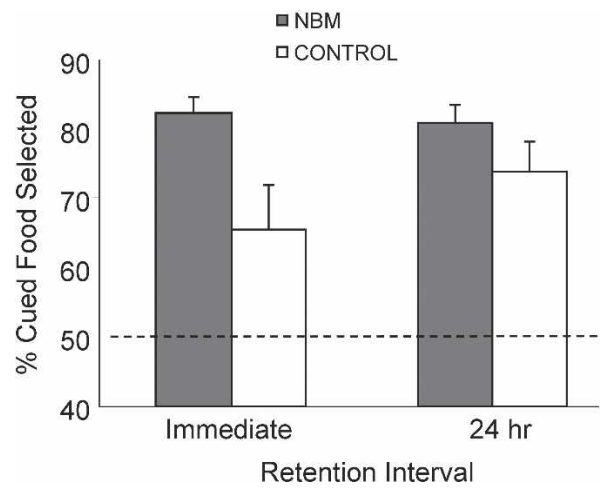

Figure 2. Percentage of cued food selected, expressed as the mean percentage $( \pm$ SEM) of the total amount of food consumed, at the two retention intervals in separate groups. NBM-stimulated rats show better performance than controls independently of delay, although the enhancement was more marked in the immediate retention than in the 24-h retention.

mental analysis. Thus, the final sample was made up of 57 rats distributed into the following groups according to treatment (NBM stimulation or control) and test delay (immediate or $24 \mathrm{~h}$ ): NBM-I $(n=15)$, Control-I $(n=14)$, NBM-24 $(n=14)$ and Control$24(n=14)$.

\section{Behavioral testing}

After NBM electrical stimulation, subjects were exposed to demonstrator rats and promptly tested for food preferences either immediately (NBM-I and Control-I) or $24 \mathrm{~h}$ later (NBM-24 and Control-24). Regarding the percentage of cued food eaten (preference for the trained food), two outliers were excluded from the main analyses $\left(t_{[14]}=9.6 ; P<0.0001 ; t_{[13]}=11.37 ; P<0.0001\right)$. The preference for the trained food was above chance in all groups (NBM-I: $t_{[13]}=13.15 ; P<0.0001$, Control-I: $t_{[13]}=2.35$; $P=0.035$, NBM-24: $t_{[12]}=12.64 ; P<0.0001$, and Control-24: $\left.t_{[13]}=5.35 ; P<0.0001\right)$, indicating that control and stimulated rats learn the task (Fig. 2). Animals learn the task equally regardless of the cued food since there were no differences in the preference for the food cued to cocoa or cinnamon $\left(F_{[1,51]}=3.01\right.$; $P=0.089$ ), and the interactions between Cued Food and Treatment, and Cued Food and Delay were also not statistically significant $\left(F_{[1,51]}=1.23 ; P=0.274, F_{[1,51]}=0.45 ; P=0.504\right)$. Importantly, General Linear Model (GLM) analyses revealed a main effect of Treatment $\left(F_{[1,51]}=7.63 ; P=0.008\right)$, but not Delay $\left(F_{[1,51]}=0.65 ; P=0.423\right)$ or interaction effects $\left(F_{[1,51]}=1.25\right.$; $P=0.269$ ) (Fig. 2). Results indicated that NBM-stimulated rats showed a stronger preference for the trained food than control rats, which was more evident in the immediate memory test.

To control for localization of the stimulation effect on the preference for the trained food, we also analyzed performance of rats with stimulation electrodes outside the NBM. This analysis demonstrated statistically significant differences in the preference for the cued food when compared with rats stimulated in the NBM $\left(F_{[1,72]}=8.27 ; P=0.005\right)$ and no differences between rats stimulated outside the $\mathrm{NBM}$ and controls $\left(F_{[1,72]}=0.26\right.$; $P=0.609$ ).

In addition to preference for the cued food, other variables were also considered. The total food consumed during retention tests was analyzed in all groups (Fig. 3) showing no statistically significant effects of Treatment $\left(F_{[1,51]}=1.52 ; P=0.223\right)$, Delay $\left(F_{[1,51]}=0.58 ; P=0.452\right)$, or interaction $\left(F_{[1,51]}=0.30 ; P=0.587\right)$, which demonstrated that NBM stimulation does not affect motivation to food consumption. To determine whether NBM treatment produced changes in neophobia, regular ground food eaten during habituation and flavored food (New Food) eaten during tests were compared. There were no statistically significant effects of Food $\left(F_{[1,51]}=1.474 ; P=0.230\right)$, Treatment $\left(F_{[1,51]}=0.345\right.$; $P=0.559)$ or interaction $\left(F_{[1,51]}=2.196 ; P=0.145\right)$, suggesting that the pattern of consumption of both foods was comparable between NBM-stimulated and control rats.

In order to rule out effects on other variables that might have affected performance in STFP, measures of social interaction were included. A sample of rats from each group was included in these additional analyses regarding social interaction and explorative behavior as recordings of some subjects during the social interactions and the test session were defective. Pearson correlation analyses showed that none of the measures of social interaction correlated significantly with the percent of cued food eaten (Table 1). As for differences between stimulated and control rats, GLM showed that Treatment did not affect any of these measures (muzzle: $F_{[1,37]}=1.09 ; P=0.304$, body: $F_{[1,37]}=0.01$; $P=0.903$, anogenital: $\left.F_{[1,37]}=0.73 ; P=0.398\right)$. The analysis of social interaction evolution throughout the three sessions demonstrated a downward lineal trend in the number of sniffs of the demonstrator's muzzle $\left(F_{[1,37]}=30.15 ; P<0.0001\right)$, body $\left(F_{[1,37]}=74.77 ; P<0.0001\right)$, and anogenital region by the observers $\left(F_{[1,37]}=45.67 ; P<0.0001\right)$, as well as a quadratic trend in the case of muzzle $\left(F_{[1,37]}=7.63 ; P=0.009\right)$ and body $\left(F_{[1,37]}=6.26\right.$; $P=0.017)$. These descending patterns were similar between groups in all cases. Other variables analyzed during the interactions were self-grooming and fighting bouts, which were not affected by Treatment $\left(F_{[1,37]}=3.84 ; P=0.058\right.$, and $F_{[1,37]}=0.44$; $P=0.510)$. Finally, jar climb data show that stimulated and control rats investigated both food jars to a similar degree $\left(F_{[1,40]}=0.698 ; P=0.408\right)$, although stimulated rats ate a greater amount from the jar containing the cued food. This indicated that NBM stimulation did not affect exploration or motor activity.

\section{Experiment 2}

After histological verification of electrode placements (AChE histochemistry), the final sample was made up of $12 \mathrm{NBM}-$ stimulated rats, eight control rats (with electrode in the NBM), and five sham rats (without electrodes). Rats implanted in the NBM (stimulated and controls) showed electrode tip placements similar to those described in Experiment 1 (Fig. 1C). As in Experiment 1 , control $(n=5)$ and stimulated $(n=7)$ subjects with the electrode outside the NBM were excluded from the main analyses, but data from stimulated rats were considered to control for the treatment specificity.

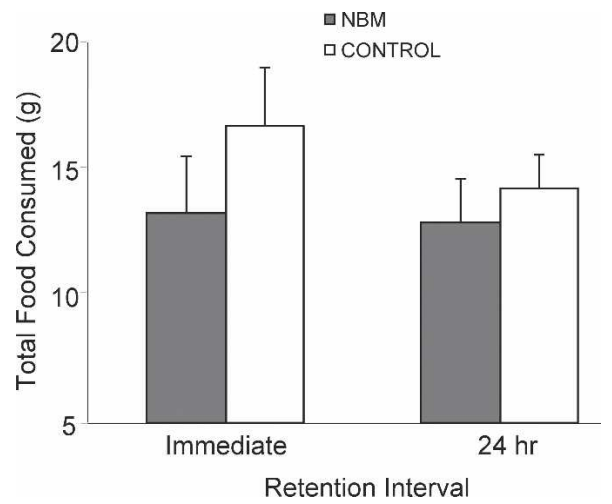

Figure 3. Total weight of food eaten $( \pm S E M)$ at the two retention intervals. The NBM-stimulated rats ate the same amount of food as controls in both the immediate and 24-h tests. 
Table 1. Correlation analysis of measures of social interaction and cued-food consumption

\begin{tabular}{|c|c|c|c|c|c|c|}
\hline \multirow[b]{2}{*}{ Behavior } & \multicolumn{3}{|c|}{ Social interaction session } & \multirow[b]{2}{*}{ Global mean } & \multicolumn{2}{|c|}{$\begin{array}{l}\text { Correlation between behavior } \\
\text { and cued-food consumption }\end{array}$} \\
\hline & 1st & 2nd & $3 r d$ & & $r$ & $P$ \\
\hline Sniffs of demonstrator's muzzle & $22.74 \pm 6.94$ & $16.36 \pm 7.01$ & $14.79 \pm 6.11$ & $53.12 \pm 13.05$ & -0.111 & 0.502 \\
\hline Sniffs of demonstrator's body & $24.64 \pm 7.58$ & $15.92 \pm 7.68$ & $11.71 \pm 5.55$ & $53.00 \pm 15.42$ & 0.155 & 0.345 \\
\hline Sniffs of demonstrator's anogenital region & $17.94 \pm 8.57$ & $13.62 \pm 8.05$ & $9.13 \pm 5.82$ & $40.58 \pm 20.07$ & -0.057 & 0.729 \\
\hline Self-grooming bouts & $0.85 \pm 1.08$ & $0.54 \pm 0.73$ & $0.48 \pm 0.73$ & $1.74 \pm 1.63$ & 0.173 & 0.291 \\
\hline Fighting bouts & $0.30 \pm 0.75$ & $0.18 \pm 0.66$ & $0.13 \pm 0.40$ & $0.66 \pm 1.43$ & -0.094 & 0.569 \\
\hline
\end{tabular}

Mean \pm SD of behaviors scored during the first $10 \mathrm{~min}$ of the three interactions and global mean \pm SD of the three interactions. Correlation analysis of the behaviors scored during the three interactions and the amount of cued food eaten during the test. None of the behaviors in the interaction sessions correlated significantly with the amount of cued food eaten.

To investigate whether prefrontal cortex, hippocampal regions, and basolateral amygdala (BLA) were activated after NBM electrical stimulation treatment, we analyzed c-Fos immunolabeling in these brain regions (Fig. 4; Table 2). Immunoreactive cells exhibited a dark nucleus in neuronal nuclei expressed clearly upon the surrounding background tissue. As there were no statistically significant differences between control and sham groups in c-Fos expression in any of the studied brain regions (all $P$-values $>0.204)$, except in infralimbic cortex (IL) $\left(F_{[1,21]}=6.19\right.$; $P=0.021)$, their data were combined into a single control group.
For IL, inter-group comparisons were carried out between NBMstimulated and control rats.

As for prefrontal cortex, there were abundant Fos-labeled cells in ventrolateral orbital cortex (VLO), where we observed a significant main effect of the treatment $\left(F_{[1,21]}=21.60\right.$; $P<0.0001)$, but not hemisphere $\left(F_{[1,21]}=0.79 ; P=0.382\right)$, or interaction between these two factors $\left(F_{[1,21]}=0.18 ; P=0.671\right)$. The same pattern of results was found in lateral orbitofrontal cortex (LO) $\left(F_{[1,21]}=20.11 ; P<0.0001, F_{[1,21]}=1.81 ; P=0.192\right.$, and $\left.F_{[1,21]}=0.96 ; P=0.338\right)$. The analysis of prelimbic cortex (PL)
PL
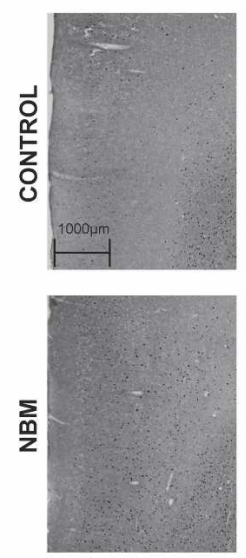

IL
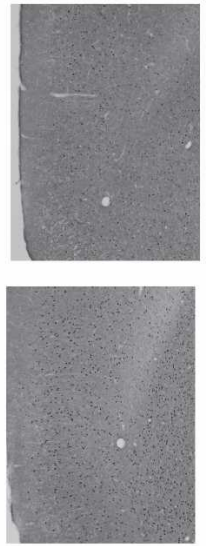

VLO
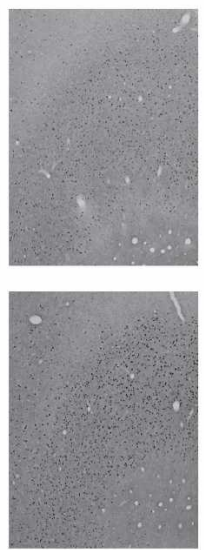

LO
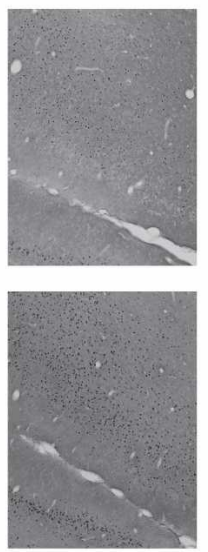

BLA
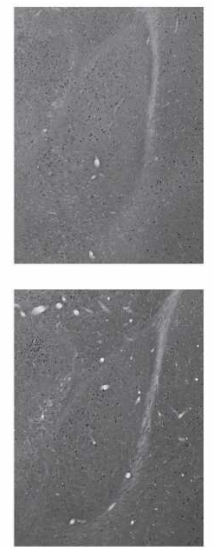

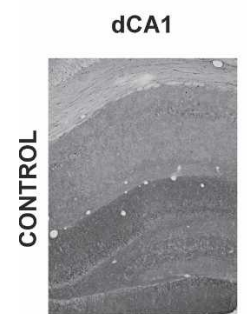

dCA2-CA3

dDG
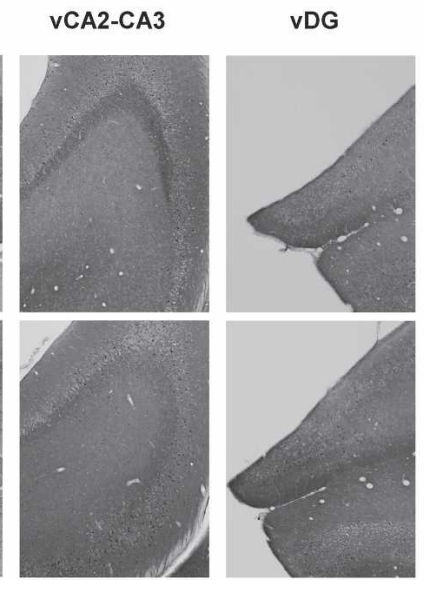

vSubiculum
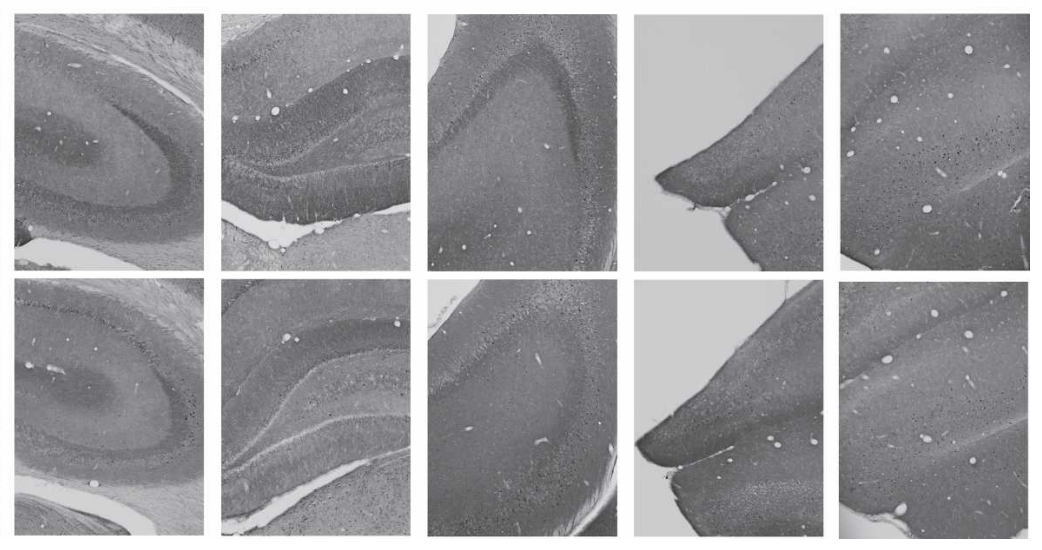

Figure 4. Representative photomicrographs of c-Fos immunostaining of control and stimulated rats in prefrontal areas: prelimbic (PL), infralimbic (IL), ventrolateral orbital (VLO), lateral orbitofrontal (LO), basolateral amygdala (BLA), and hippocampus subfields: dorsal CA1 (dCA1), dorsal CA2-CA3 (dCA2-CA3), dorsal dentate gyrus ( $d D G$ ), ventral CA2-CA3 (vCA2-CA3), ventral dentate gyrus (vDG), and ventral subiculum (vsubiculum). NBMstimulated rats had more immunolabeled cells than control rats in all the prefrontal areas, dorsal CA, and ventral DG. 
also revealed a statistically significant treatment effect $\left(F_{[1,22]}=16.93 ; P<0.0001\right)$, but not hemisphere $\left(F_{[1,22]}=4.29\right.$; $P=0.053)$, or interaction $\left(F_{[1,22]}=2.40 ; P=0.135\right)$. In the IL we also detected a significant treatment effect $\left(F_{[1,18]}=7.861\right.$; $P=0.012)$ but not hemisphere $\left(F_{[1,18]}=0.000 ; P=0.996\right)$, or interaction $\left(F_{[1,18]}=2.549 ; P=0.128\right)$.

Stimulated rats also exhibited a significantly higher number of c-Fos-labeled cells compared with control rats in the dorsal hippocampus: dCA1 $\left(F_{[1,23]}=7.853 ; P=0.010\right)$ and dCA2-CA3 $\left(F_{[1,23]}=5.16 ; P=0.033\right)$, and the ventral dentate gyrus (vDG) $\left(F_{[1,20]}=6.77 ; P=0.017\right)$. These effects were always irrespective of the hemisphere (all $F$-values $<3.44$; all $P$-values $>0.078$ ), and, although no interactions between treatment and hemisphere were found in dCA2-CA3, vDG (all $F$-values $<0.0001$; all $P$-values $>0.998)$, the interaction was statistically significant in dCA1 $\left(F_{[1,23]}=5.47 ; P=0.028\right)$. However, NBM stimulation treatment did not increase the number of fos-labeled cells in the ventral CA2-CA3 $\left(F_{[1,23]}=3.637 ; P=0.069\right)$, the ventral subiculum $\left(F_{[1,22]}=2.16 ; P=0.156\right)$, or the dorsal DG $\left(F_{[1,23]}=0.163\right.$; $P=0.690)$. We found no statistical differences regarding hemisphere (all $F$-values $<2.383$; all $P$-values $>0.137$ ) or interactions between treatment and hemisphere (all $F$-values $<2.04$; all $P$-values $>0.167)$.

BLA showed a modest number of immunoreactive cells in both stimulated and control animals, and no significant differences were found between groups $\left(F_{[1,22]}=3.196 ; P=0.088\right)$, regarding hemisphere $\left(F_{[1,22]}=0.641 ; P=0.432\right)$ or interaction $\left(F_{[1,22]}=2.409 ; P=0.135\right)$.

As in Experiment 1, the analysis of rats stimulated outside the NBM showed no differences with the control rats in any of the regions studied (VLO: $F_{[1,27]}=0.14 ; P=0.712$, LO: $F_{[1,27]}=4.06 ; P=0.054$, PL: $F_{[1,27]}=0.50 ; P=0.484$, IL: $F_{[1,21]}=0.01 ; P=0.936, \mathrm{dCA} 1: F_{[1,29]}=0.12 ; P=0.727, \mathrm{dCA} 2-$ CA3: $F_{[1,29]}=0.05 ; P=0.831, \mathrm{dDG}: F_{[1,29]}=2.81 ; P=0.104$, vCA2-CA3: $F_{[1,29]}=0.30 ; P=0.589$, ventral DG: $F_{[1,26]}=0.13$; $P=0.726$, ventral subiculum: $F_{[1,27]}=0.11 ; P=0.742$, and BLA: $\left.F_{[1,28]}=0.04 ; P=0.848\right)$. Moreover, there were statistically significant differences between rats stimulated outside and inside the NBM in the regions where differences between control and NBMstimulated rats were detected (VLO: $F_{[1,27]}=14.92 ; P=0.001$, LO: $F_{[1,27]}=32.16 ; P<0.0001$, PL: $F_{[1,28]}=6.65 ; P=0.015$, IL: $F_{[1,21]}=9.40 ; P=0.005$, dorsal CA1: $F_{[1,29]}=8.07 ; P=0.008$, dorsal CA2-CA3: $\left.F_{[1,29]}=4.62 ; P=0.040\right)$. In ventral CA2-CA3, significant differences were also revealed between the two stimulated groups $\left(F_{[1,29]}=4.74, P=0.038\right)$. A tendency to statistically significant differences was found in dorsal DG $\left(F_{[1,29]}=4.12\right.$; $P=0.052)$ and ventral DG $\left(F_{[1,27]}=3.82 ; P=0.062\right)$, and no significant differences were detected in the ventral Subiculum $\left(F_{[1,28]}=0.95 ; P=0.339\right)$ or BLA $\left(F_{[1,28]}=3.17 ; P=0.086\right)$.

In short, NBM-stimulated rats showed more immunolabeled cells than control rats in all the prefrontal cortical areas and some hippocampal subregions (dorsal CA and ventral DG), irrespective of the hemisphere. In contrast, no differences between groups in Fos expression were found in BLA, dorsal DG, ventral CA, and ventral subiculum.

\section{Discussion}

Present behavioral results indicate that pretraining stimulation of the NBM facilitates STFP, a relational odor-odor association task. The treatment improved the STFP retention regardless of when the test was conducted, either immediately or $24 \mathrm{~h}$ after training. It is unlikely that the observed improvement in STFP is secondary to performance factors such as the amount of social interaction, motivation to eat, or changes in neophobia or exploration, since none of these variables was affected by the stimulation treatment. Results of Experiment 2 indicated that electrical stimulation of the NBM led to bilateral increased c-Fos expression in prefrontal regions, such as OFC, PL, and IL, and some hippocampal subregions.

Current findings expand on previous data showing that NBM electrical stimulation improves acquisition of an implicit two-way active avoidance task (Montero-Pastor et al. 2004). Our results are also consistent with others previously reported demonstrating that the cholinergic cells of NBM are involved in acquisition and memory formation of STFP (Berger-Sweeney et al. 2000; Vale-Martinez et al. 2002). There are indeed more studies suggesting a role of NBM in learning and memory processes. For instance, NBM lesions affected other tasks such as visual discrimination learning (Ridley et al. 2005), learning set formation (Bailey et al. 2003), and appetitive-to-aversive transfer learning (Butt et al. 2003). Therefore, facilitation in the acquisition of the STFP might be assumed and related to enhancements in the stimulus encoding or the initial formation of the critical association between the two significant stimuli for the task (food odor and odor of carbon disulfide). Although our results might be interpreted as pointing toward NBM stimulation-induced improvement in the learning of information concerning socially transmitted preferences, a number of reports suggest that the NBM may have an important role in attentional processes. Tasks that place specific demands on attention appear to be sensitive to NBM lesions, mainly those assessing operant measures of sustained attention (McGaughy et al. 1996, 2002; Robbins 2002), and also selective attention tasks (Muir et al. 1992) or divided attention paradigms (Turchi and Sarter 1997; Waite et al. 1999). In the current research, although we cannot distinguish attentional enhancement from learning enhancement, an interpretation purely derived from attentional facilitation would not be appropriate since STFP does not specifically tax attention.

In view of the critical role of the cholinergic system in modulation of olfactory learning and social recognition memory (Ross et al. 2005; for review, see Vale-Martinez et al. 2002), augmentation of cortical ACh by NBM electrical stimulation may be an important factor to understand the present results. Application of optimal electrical stimulation of NBM may provide spatial and temporal characteristics of ACh release that are consistent with the normal anatomy and physiology of the NBM cholinergic system (Rasmusson 2000) and thus may facilitate cognitive function. Parameters used in the current research are similar to those used in other studies in which NBM stimulation elicited large increases in cortical ACh release (Rasmusson 2000), cortical EEG activation (McLin III et al. 2002, 2003; Golmayo et al. 2003), and cortical plasticity (Weinberger 2003). However, the activation of other neuronal populations (probably noradrenergic or GABAergic) may also contribute to the effects found on STFP (Gritti et al. 2003; Manns et al. 2003). The functions of the GABAergic cells, which appear to work together with the NBM cholinergic neurons to produce cortical plasticity (JimenezCapdeville et al. 1997; McKinney and Jacksonville 2005), may mediate executive aspects of cognitive performance (Sarter and Bruno 2002).

As for the molecular consequences of NBM electrical stimulation, the treatment induced increases in c-Fos expression in prefrontal regions, such as OFC, PL, and IL cortices, and some hippocampal regions (dorsal CA1, CA2-CA3, and ventral DG). Nevertheless, effects of NBM stimulation on c-Fos immunoreactivity were not revealed in any other areas of the hippocampus (ventral CA2-CA3, ventral subiculum, and dorsal DG) or the BLA. Some of the regions where activation was enhanced by NBM stimulation coincide with cortical and hippocampal areas activated in certain STFP phases or with areas required for the task. 
The area demonstrating a higher increase in c-Fos expression after NBM stimulation is the OFC (VLO and LO), which has been implicated in odor-guided learning (Otto and Eichenbaum 1992; Whishaw et al. 1992; Lipton et al. 1999; Roullet et al. 2005) and specifically in STFP (Ross et al. 2005). Ross et al. (2005) reported that cholinergic deafferentiation of OFC prior to STFP training impaired expression of the task tested $2 \mathrm{~d}$ later, supporting that $\mathrm{ACh}$ in the OFC may be essential for the encoding of the new information required for the task. In that respect, the OFC has been shown to participate in encoding the value of olfactory stimuli (Schoenbaum et al. 1998; Saddoris et al. 2005) as it belongs to a network that integrates stimulus significance and other types of information to select appropriate behavioral responses. Even so, it is also possible that the OFC lesion in the Ross et al (2005) study caused impairment in STFP retrieval as a recent study of c-fos expression reports that this cortex is activated increasingly in successive retrieval tests, showing a trend toward significant activation $2 \mathrm{~d}$ after acquisition and a higher activation during retrieval $21 \mathrm{~d}$ after (Ross and Eichenbaum 2006). This pattern of findings suggests that NBM stimulation may have facilitated STFP (an odor-odor association task) as it activated structures such as VLO and LO, critically involved in STFP acquisition and/or retrieval.

Other prefrontal subregions showing a large number of immunoreactive cells following NBM electrical stimulation are PL and IL. One may consider that PL-IL activation induced by NBM stimulation prior to training might contribute to a better STFP acquisition, but IL failed to show significant differences between STFP-trained animals and controls in the number of cells expressing c-Fos at different retrieval times (Ross and Eichenbaum 2006). As for PL, it has not been directly studied in relation to STFP, but it has been shown that damage to the parafascicular nucleus, which projects to PL-IL, prevents STFP learning (Quiroz-Padilla et al. 2006). The authors interpret their results in the context of medial prefrontal cortex deafferentiation induced by the thalamic lesion. Moreover, PL is involved in working memory, attentional selectivity to relevant stimulus features during learning, and participates in behavior flexibility (Dalley et al. 2004). Some of these functions are shared with the NBM (Chudasama et al. 2004), which, acting through this region, might improve processes such as behavior flexibility, necessary for the STFP. Stimulation of the NBM could therefore enhance some of the functions of the prefrontal cortex or, at least, those involving the integration of relationships based on previous experience, thus allowing the expression of adaptative behavior in novel circumstances.

Our data also showed that NBM electrical stimulation, at parameters enhancing STFP, caused increases in c-Fos expression in dorsal CA and ventral DG, but not in ventral CA, ventral subiculum, or dorsal DG. The observation of c-Fos induction in hippocampal formation is rather unforeseen as it is an area not directly supplied by cholinergic projections arising from the NBM (Mesulam et al. 1983). Nevertheless, this is not the first report supporting the hypothesis of indirect connections between NBM and hippocampus. There is evidence that NBM lesions cause neurodegenerative changes of hippocampal mossy fibers and DG (Amenta et al. 1991; Panocka et al. 1995) and increase NADPH-diaphorase in the dorsal CA1-CA3 fields of the hippocampus (Sabbatini et al. 1999). The data from present research are relevant in view of a previous study showing increases in c-Fos expression in the dorsal CA3 and ventral DG following a STFP test (carried out $1.5 \mathrm{~h}$ after training) of trained rats in comparison with social + odor control rats (Countryman et al. 2005b). The same study also showed greater c-Fos expression in ventral DG in STFP-trained rats compared with social-controls following either acquisition or a 2-d recall test. The involvement of ventral hippocampus in this task is also pointed out in another study showing ventral subiculum activation during retrieval shortly after learning and a decline in the level of activation at successive times (Ross and Eichenbaum 2006). In the current experiment, although NBM-stimulated rats showed more immunoreactive cells in the ventral subiculum than controls, no statistically significant differences were found between groups. Nevertheless, hippocampal-lesioned rats normally acquire and briefly retain the food odor association as demonstrated by intact memory immediately after social training (Bunsey and Eichenbaum 1995), and it has been reported that hippocampal administration of $c$-fos antisense impairs long-term STFP memory as tested two weeks after training but leaves immediate memory intact (Countryman et al. 2005a). Accordingly, increases in c-Fos expression in dorsal CA or ventral DG after pretraining NBM stimulation might better account for 24-h retention facilitation as opposed to the greater immediate retention, which might be better explained by prefrontal activation, as discussed above.

NBM electrical stimulation did not alter c-Fos expression in the BLA even though NBM neurons provide the major cholinergic innervation to the amygdala (Mesulam et al. 1983). A factor that may justify this unexpected result is that the stimulation current intensity and the specific neuronal population affected by electrodes in these experiments are not the most appropriate for obtaining amygdala activation. Parameters chosen in the present research were similar to those from studies in which NBM stimulation elicited large increases in cortical activity (Rasmusson 2000). Corticopetal and amygdalopetal neurons differ neurobiologically in some aspects, and it thus seems likely that they may also differ in their neurophysiology.

The use of electrical stimulation does not allow us to determine whether neuronal perikarya, axons of passage, or both, were stimulated. Nevertheless, the accurate electrode placement, the relatively low levels of current, the regional-specific effects in c-Fos expression, and the similar results (in Experiments 1 and 2) observed in rats stimulated in the vicinity of the NBM and control rats suggest that stimulation is specific and reasonably well confined to the NBM.

In summary, current data show that pretraining NBM electrical stimulation facilitates the acquisition of STFP, suggesting that the treatment might induce neural changes related to transcription factors such as c-Fos, which may be relevant in accounting for those effects in socially transmitted preferences. Since c-Fos expression was significantly increased following NBM stimulation in prefrontal cortex and some hippocampus regions that have been shown to be relevant for odor-associative memory (Ross et al. 2005; Ross and Eichenbaum 2006), NBM contribution to STFP may be mediated by these regions.

\section{Materials and Methods}

\section{Experiment 1}

\section{Subjects}

Eighty-one male Wistar rats (obtained from our laboratory breeding stock) weighing $419.4 \mathrm{~g}(\mathrm{SEM}=4.45)$ and $98.23(\mathrm{SEM}=0.78)$ days old at the beginning of the experiment were used as observer subjects. An additional set of 58 juvenile Wistar male rats (mean age $=35.18 \mathrm{~d}$, SEM =0.92), weighing $169.19 \mathrm{~g}$ $(\mathrm{SEM}=5.43)$ at the beginning of the experiment, served as demonstrator subjects. A separate set of 30 male Wistar rats were used as pilot subjects to test the innate preference between different odor pairs (cocoa-cinnamon, and anise-oregano) and showed preference for anise versus oregano, but no distinct preference for either component of the pair $2 \%$ cocoa- $1 \%$ cinnamon. This pilot study confirmed that three social interactions with demonstrator animals were necessary to show a robust memory for the STFP task. 
Throughout the experiment the observers were housed singly in $22 \times 22 \times 14$-cm plastic-bottomed cages with sawdust bedding, and the demonstrators in groups of four in $50 \times 22 \times 14$-cm cages, maintained on a 12-h light/12-h dark cycle in a humidity- and temperature-controlled environment. Surgery and behavioral testing were performed during the light phase of the cycle. Rat-chow pellets (Panlab SL, A04) and water were provided ad libitum except during pretraining, training, and testing for the task. In such phases, the rats were submitted to a food restriction schedule (five pellets/day for observers and four pellets/day for demonstrators) to be maintained at $85 \%$ of basal body weight. The animals were weighed and handled for 5 min every day, depending on the procedures they underwent. Experiments were carried out in accordance with the European Community Council Directive for care and use of laboratory animals (86/609/ECC) and with Generalitat de Catalunya authorization (DOGC 2450 7/8/1997, DARP protocol number 2265).

\section{Surgery}

The observer animals were randomly assigned to one of the following four groups: Two groups underwent a retention session immediately after learning (NBM-I and Control-I), and two groups a retention session $24 \mathrm{~h}$ after learning (NBM-24 and Control-24). Animals were anesthetized with i.p. Ketamine hydrochloride (Ketolar, 90 mg/kg; Parke-Davis) and xylazin (Rompun, $8 \mathrm{mg} / \mathrm{kg}$; Bayer) and placed in a stereotaxic head holder (Model 1504, Kopf Instruments). The skull was exposed through a midline incision and leveled along the bregma-lambda axis. All the rats were implanted in the right or left hemisphere, in a balanced way for each group, with one monopolar stainless steel electrode that was electrically insulated except for the tip (Plastics One, Bilaney; $150 \mu \mathrm{m}$ in diameter). Stereotaxic coordinates were used: AP: $-1.10 \mathrm{~mm}$ from bregma; ML: $\pm 2.8 \mathrm{~mm}$ from midline, and DV: $-7.6 \mathrm{~mm}$ from cranium surface (Paxinos and Watson 1997). The electrodes were soldered to a plastic connector that was anchored to the skull with jeweler screws and dental cement (Vertex self-curing, Dentimex). The grounding electrode was a copper wire (200 $\mu \mathrm{m}$ in diameter) with one end soldered to the electrode connector and the other to a screw. Rats in control groups were implanted in the NBM without a grounding electrode. After surgery, the skin was sutured and antiseptic was applied (Topionic, Almirall Prodesfarma) to the sutured area. Rats were returned to their home cages and allowed $10 \mathrm{~d}$ ( $4 \mathrm{~d}$ for recovery, $4 \mathrm{~d}$ for food deprivation, and $2 \mathrm{~d}$ for rehabituation) before behavioral testing.

\section{Behavioral apparatus}

All observer habituation, training, and testing were conducted in $50 \times 22 \times 14$-cm plastic-bottomed cages with sawdust bedding. Habituation and testing were carried out presenting the animals with a feeding tray placed in their cage. The tray consisted of a black Plexiglas base $(21 \times 21 \mathrm{~cm})$ with two adjacent plastic pots fixed onto the center of the base. The food was placed in two glass jars $(130 \mathrm{~mL})$ secured within each plastic pot. For the demonstrators, habituation and training were carried out in $22 \times 22 \times 14-\mathrm{cm}$ plastic cages allowing them to eat from a glass jar mounted upon the center of a black Plexiglas base $(21 \times 10$ $\mathrm{cm})$.

\section{Habituation to food jars}

After $7 \mathrm{~d}$ of food deprivation and prior to surgery, rats were habituated to eating plain ground rat chow (Panlab SL, A04) from glass jars to minimize neophobia for $2 \mathrm{~h}$ on the first day, $1 \mathrm{~h}$ the second day, and $45 \mathrm{~min}$ the third day. During the three habituation sessions, the rats were presented with food cups in feeding trays containing ground, unflavored rat chow. The amount of food eaten was determined, and only rats eating at least $2 \mathrm{~g}$ of food on the last day were included in the study. Two observer rats were excluded from the current experiment based on this criterion. A similar procedure was repeated $7 \mathrm{~d}$ after surgery (two 45-min rehabituation sessions). Subsequently, animals were food-deprived once again for $2 \mathrm{~d}$ before the training-testing sessions began.

\section{Intracranial electrical stimulation in the NBM}

Immediately before training to the STFP task, rats received a 20-min stimulation session, during which they were free to move. The treatment was applied in a stimulation cage $(26.5 \times 30.5 \times 35 \mathrm{~cm})$ made of Plexiglas. The electrical current delivered by a stimulator (Model CS-20, Cibertec) consisted of $1-\mathrm{Hz}$ square pulse trains of $500 \mathrm{msec}$. Each train contained 50 pulses of 0.5 -msec duration. Current intensity was $100 \mu$ A. Such parameters were similar to those in other studies reporting large increases in ACh release (Rasmusson 2000), cortical EEG activation (McLin III et al. 2002, 2003; Golmayo et al. 2003), and facilitation of learning and memory (Montero-Pastor et al. 2001, 2004). The animals' behavior was monitored during the stimulation session and no striking alterations (i.e., agitation, motor stereotypes) were detected. Control rats were placed in the same cage for $20 \mathrm{~min}$ with the electrode clip connected but were never stimulated.

\section{STFP training and testing}

Before training was conducted, each rat in the stimulation and control groups was assigned randomly to be cued to one of the two components of the odor pair. Rats were habituated to the training cage and room for $30 \mathrm{~min}$ immediately before stimulation and training. Training to the task began when a demonstrator rat was allowed to eat food cued to $2 \%$ cocoa (Cadbury Ltd.) or 1\% cinnamon (Carmencita) for 30 min. Demonstrator animals were only used if they had eaten at least $1 \mathrm{~g}$ of flavored chow (all rats met this criterion). Subsequently, a demonstrator that had just eaten flavored chow was placed into the observer's cage. The two rats were allowed to interact with no barriers for $20 \mathrm{~min}$, following which the demonstrator was removed. This procedure was repeated twice at 1-h intervals, each time using a different demonstrator who had eaten the same odorant.

Subjects were tested immediately (NBM-I and Control-I groups) after the third interaction or $24 \mathrm{~h}$ after training (NBM-24 and Control-24 groups). During testing, the observer rat was presented with two jars of food (one containing the cued food and the other the noncued i.e., the distractor food) with water available. The location of the trained odor (left or right) was balanced across animals. The observers were allowed to eat for $45 \mathrm{~min}$, after which both food jars were removed and weighed to determine the amount of food eaten from each. A "preference score" (percent of cued food selected) for the trained odor (e.g., cocoa) was calculated as follows: $100 \times$ weight of food cued on cocoa eaten/weight of all food eaten. Subjects' behavior during the three social interactions and testing was recorded on a video camera (Panasonic RX22) connected to a monitor. We scored the number of times each observer sniffed the muzzle, body, or anogenital region of the demonstrator, as well as grooming and fighting bouts. A "sniff" was defined as close orientation $(<2 \mathrm{~cm})$ of the observer's muzzle toward the demonstrator (Wrenn et al. 2003). During the testing, we scored the number of times the rat was observed to be on top of the jar with both forepaws (jar climbs).

\section{Histology}

Upon completion of behavioral testing, all observers were deeply anesthetized with an overdose of sodium pentobarbital (Dolethal Vetoquinol SA; $200 \mathrm{mg} / \mathrm{kg}$ i.p.) and were perfused transcardially with $100 \mathrm{~mL} 0.1 \mathrm{M}$ phosphate-buffered saline (PBS) followed by $250 \mathrm{~mL} 4 \%$ paraformaldehyde in $0.1 \mathrm{M}$ PBS at a flow rate of $40 \mathrm{~mL} / \mathrm{min}$. Brains were post-fixed in the perfusion solution for $2 \mathrm{~h}$ and then cryoprotected in a 30\% sucrose PBS solution for $48 \mathrm{~h}$. Brains were sectioned at $40 \mu \mathrm{m}$ thickness proximal to the electrode placements on a cryostat (Cryocut 1800 with microtome 2020 Reichert-Jung). The sections were processed for acetylcholinesterase (AChE) histochemistry, essentially as described elsewhere (Paxinos and Watson 1997), and examined under a microscope (Olympus BX 41, Olympus Optical CO Ltd.). To localize electrode placement into the NBM, microphotographs were taken (Olympus DP 70, Microscope Digital Camera, Olympus Optical CO Ltd.) and examined by two independent observers. 


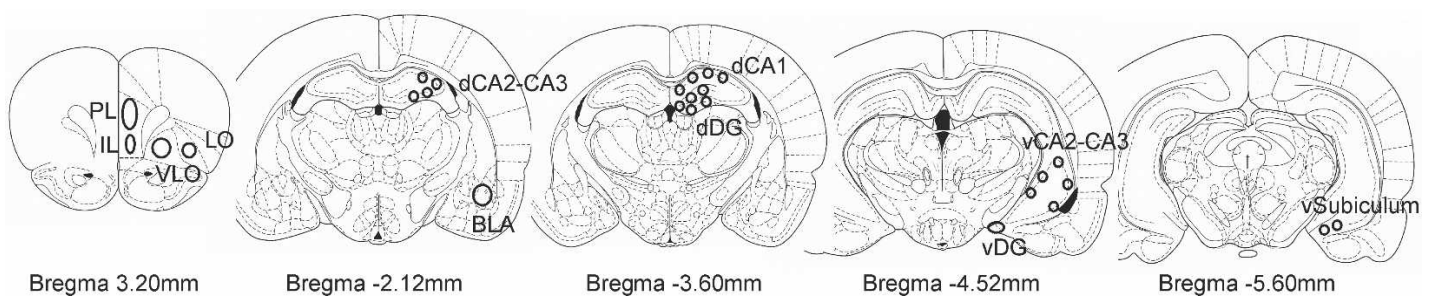

Figure 5. Representation of the areas sampled. Prelimbic (PL), infralimbic (IL), ventrolateral orbital (VLO), lateral orbitofrontal (LO), basolateral amygdala (BLA), and hippocampus subfields: dorsal CA1 (dCA1), dorsal CA2-CA3 (dCA2-CA3), dorsal dentate gyrus (dDG), ventral CA2-CA3 (vCA2CA3), ventral dentate gyrus (vDG), and ventral subiculum. Reprinted with permission from Elsevier ( ) 1997, Paxinos and Watson (1997).

\section{Data analysis}

A first analysis was performed using General Lineal Model (GLM; SPSS v12 software, SPSS Iberica), in which the factors were "Treatment" (NBM or control), "Delay" (immediate or $24 \mathrm{~h}$ ), and "Food Cued" (cocoa or cinnamon) and the dependent variable was "Percent of Cued Food" (considered as the preference). As the factor Food Cued was found not to be significant, the main analyses were performed by means of GLM in which the factors were Treatment, Delay and the dependent variable was Percent of Cued Food. A one-sample $t$-test was used to study the outliers from the sample. Another one-sample $t$-test against a constant (50) was used for each group to determine if the percent of cued food eaten was greater than the chance level (50\%). To control for the specificity of the stimulation, a GLM analysis was performed in which the factor was Treatment (stimulated NBM, control, stimulated outside NBM) and the dependent variable was Percent of Cued Food.

Additional analyses were carried out to evaluate possible changes induced by the stimulation in other variables measured during the social interactions and the tests. We analyzed the first $10 \mathrm{~min}$ of the three social interactions using the GLM for repeated measures (three sessions) with corresponding contrasts, in which the dependent variables were "Sniffs of Demonstrator's Muzzle," "Sniffs of Demonstrator's Body," "Sniffs of Demonstrator's Anogenital Region," "Self-Grooming Bouts," and "Fighting Bouts." Pearson correlation and linear regression were performed between these variables and Percent of Cued Food. Regarding the test, a GLM for repeated measures with corresponding contrasts

Table 2. c-Fos analyses

\begin{tabular}{|c|c|c|c|c|}
\hline \multirow[b]{3}{*}{ Region } & \multicolumn{4}{|c|}{ Groups } \\
\hline & \multicolumn{2}{|c|}{ NBM } & \multicolumn{2}{|c|}{ Control } \\
\hline & Ipsilateral & Contralateral & Ipsilateral & Contralateral \\
\hline \multicolumn{5}{|l|}{ Prefrontal cortical areas } \\
\hline $\mathrm{PL}^{\mathrm{a}}$ & $222.82 \pm 112.68$ & $356.46 \pm 106.85$ & $187.36 \pm 81.85$ & $200.9 \pm 64.28$ \\
\hline $\mathrm{IL}^{\mathrm{a}}$ & $419.94 \pm 124.24$ & $390.61 \pm 79.49$ & $242.93 \pm 94.17$ & $263.11 \pm 99.38$ \\
\hline $\mathrm{VLO}^{\mathrm{a}}$ & $745.09 \pm 152.53$ & $776.35 \pm 117.38$ & $516.26 \pm 159.84$ & $527.18 \pm 110.45$ \\
\hline $\mathrm{LO}^{\mathrm{a}}$ & $620.30 \pm 125.04$ & $628.88 \pm 113.34$ & $389.26 \pm 97.48$ & $443.63 \pm 155.77$ \\
\hline Basolateral amygdala & $79.22 \pm 35.11$ & $63.66 \pm 34.58$ & $47.23 \pm 26.41$ & $52.20 \pm 38.31$ \\
\hline \multicolumn{5}{|c|}{ Hippocampal subregions } \\
\hline \multicolumn{5}{|c|}{ Dorsal } \\
\hline $\mathrm{CA} 1^{\mathrm{a}}$ & $109.61 \pm 71.31$ & $83.63 \pm 49.48$ & $41.63 \pm 36.07$ & $44.94 \pm 37.35$ \\
\hline $\mathrm{CA} 2-\mathrm{CA}^{\mathrm{a}}$ & $77.68 \pm 38.40$ & $74.48 \pm 25.72$ & $47.65 \pm 34.67$ & $44.67 \pm 39.22$ \\
\hline DG & $88.89 \pm 48.93$ & $85.55 \pm 50.91$ & $78.46 \pm 86.20$ & $76.41 \pm 71.83$ \\
\hline \multicolumn{5}{|l|}{ Ventral } \\
\hline CA2-CA3 & $158.55 \pm 59.58$ & $166.91 \pm 57.86$ & $117.77 \pm 50.84$ & $126.39 \pm 56.53$ \\
\hline $\mathrm{DG}^{\mathrm{a}}$ & $430.51 \pm 86.53$ & $394.98 \pm 135.05$ & $296.76 \pm 181.21$ & $238.24 \pm 155.41$ \\
\hline Subiculum & $212.58 \pm 99.54$ & $178.38 \pm 84.17$ & $142.48 \pm 85.07$ & $141.16 \pm 104.74$ \\
\hline
\end{tabular}

Mean \pm SD cell counts $/ \mathrm{mm}^{2}$ for c-Fos in standard areas of the prefrontal cortex, amygdala, and dorsal and ventral hippocampal subregions. Control group includes rats with an electrode but no stimulation (control) and rats without an electrode (sham), except for IL (electrode control only).

a $P<0.05$ : Statistically significant differences were found between NBM and control groups, regardless of hemisphere, as tested by GLM.

CA, cornu ammonis; DG, dentate gyrus; IL, infralimbic; LO, lateral orbitofrontal; NBM, nucleus basalis magnocellularis; PL, prelimbic; VLO, ventrolateral orbital. was carried out to analyze neophobia, with the dependent variables "Regular Food" (mean g of food eaten during two sessions of habituation just prior to training) and "New Food "(total food eaten during the test). "Total Food Eaten" and "Jar Climbs" were analyzed in the same way to evaluate motivation to eat and exploration.

\section{Experiment 2}

\section{Subjects}

The subjects were 37 naive male Wistar rats obtained from our laboratory breeding stock, with a mean age of $100.32 \mathrm{~d}$ $(\mathrm{SEM}=1.45)$ and a mean weight of $445.40 \mathrm{~g}(\mathrm{SEM}=4.18)$ at the beginning of the experiment. The rats were maintained with the same procedures as in Experiment 1, but were not fooddeprived.

\section{Surgery and stimulation}

Rats were randomly distributed into three groups before surgery: NBM (stimulated in the NBM), control (with electrode in the NBM, but not stimulated), and sham (with surgical procedures Immunohistochemistry

Two hours after a single 20-min session of electrical stimulation in the NBM, all rats were anaesthetized as in Experiment 1 . The animals were sacrificed $2 \mathrm{~h}$ after treatment as this delay corresponds to the maximal c-Fos expression following a variety of stimulation situations (Herrera and Robertson 1996). The rats were then perfused transcardially with $100 \mathrm{~mL}$ of $4^{\circ} \mathrm{C}$ saline solution $(0.9 \%$ $\mathrm{NaCl})$ and $250 \mathrm{~mL}$ of $4^{\circ} \mathrm{C}, 4 \%$ paraformaldehyde. Brains were submerged in the perfusion solution overnight and then transferred to a $30 \%$ sucrose cryoprotectant solution for $48 \mathrm{~h}$. Brains were frozen with a cryogen spray (SHUR/freeze, TBS) and stored at $-80^{\circ} \mathrm{C}$ until they were sectioned on a cryostat. Representative coronal $25-\mu \mathrm{m}$ sections throughout the whole brain were obtained and stored at $-20^{\circ} \mathrm{C}$ in a cryoprotectant solution (30\% ethyleneglycol, $20 \%$ glycerol in $0.25 \mathrm{mM}$ phosphate buffer at $\mathrm{pH}$ 7.3) until further processing. To evaluate correct electrode implantation, sections proximal to the electrode placements were collected onto slides and processed for AChE histochemistry.

Fos immunohistochemistry was performed on floating sections under agitation. Endogenous per-

\section{Learning \& Memory}


oxidase was blocked with a solution at $0.3 \% \mathrm{H}_{2} \mathrm{O}_{2}, 0.1 \%$ sodium azide in potassium phosphate buffer saline $(0.2 \mathrm{M} \mathrm{NaCl}, 43 \mathrm{mM}$ potassium phosphate, KPBS) and nonspecific binding was reduced by incubating with a blocking solution containing $0.4 \%$ Triton X-100 and 3\% nonfat milk in KPBS. Sections were incubated in a c-Fos rabbit polyclonal primary antibody (1:500; Santa Cruz Biotechnology) overnight at $4^{\circ} \mathrm{C}$. Subsequently, sections were incubated in biotinylated goat anti-rabbit secondary antibody (1:200; Southern Biotechnology Assoc.) for $1 \mathrm{~h}$ at room temperature. Finally, sections were processed with streptavidin labeled with horseradish peroxidase (1:400; Southern Biotechnology Assoc.) for $1 \mathrm{~h}$ at room temperature. The c-Fos antibodyperoxidase complex was revealed using 0.05\% 3,3'-diaminobenzidine (Sigma) and $0.015 \% \mathrm{H}_{2} \mathrm{O}_{2}$ in KPBS. Sections were mounted onto gelatin-coated slides, dehydrated with ethanol series and coverslipped with DPX (Panreac Química SA).

\section{Quantitative analysis of fos-like immunoreactivity (FLI)}

Mounted sections of the tissue were photographed with a digital camera (DP-70, Olympus, Olympus Optical Co. Ltd.) attached to a microscope (BX-41, Olympus, Olympus, Optical Co. Ltd.). Images were taken with a $10 \times$ magnification from different areas such as ventrolateral orbital (VLO), lateral orbitofrontal (LO), prelimbic (PL), infralimbic (IL), as well as basolateral amygdala (BLA), and hippocampal regions: dorsal and ventral CA, dorsal and ventral dentate gyrus (DG), and ventral subiculum. The brain regions were photographed at the same coordinates in each animal, using the stereotaxic atlas of Paxinos and Watson (Paxinos and Watson 1997) as a reference (Fig. 5). Special care was taken to ensure that all images were taken under the same lighting conditions.

Quantification of fos-like immunoreactive (FLI) nuclei was performed using the freeware Image Processing and Analysis in Java 1.33 (ImageJ, NIH, available at http://rsb.info.nih.gov/ij/). For the quantification, an automated algorithm implemented on a macro was used. Briefly, for each brain area, a region of interest was drawn and stored to use in all the rats. To avoid differences between immunostaining batches, each image was digitally smoothed, and the resulting image was subtracted from the original one. The appropriate gray threshold and particle size were set for each area and maintained for all subjects. All brain regions were bilaterally counted in three sections for each rat. The mean number of FLI nuclei per $\mathrm{mm}^{2}$ for each region of interest, considering the average of the three sections, is shown in Table 2 . To control the efficacy of the automatic quantification, a final step was included in the macro, which consisted of merging in different colors the original image and the image resulting from the particle detection.

\section{Data analysis}

Cell counts per $\mathrm{mm}^{2}$ were analyzed for each brain structure using a GLM analysis with one between-subject factor, the "Treatment" condition (NBM or control) and one within-subject factor, the "Hemisphere" (stimulation side: ipsi or contralateral to electrode placement). As in Experiment 1, ancillary GLM analyses of cell counts per $\mathrm{mm}^{2}$ were performed for each structure, in which the factor Treatment comprised three groups (stimulated NBM, control, stimulated outside NBM).

\section{Acknowledgments}

This research was supported by funds provided by the Universitat Autònoma de Barcelona (UNI/2078/202), Generalitat de Catalunya (2002SGR0080, SGR2005-00551), and by the Ministerio de Ciencia y Tecnologia (BSO2002-03441, SEJ2005-02518). We thank the Area de Fisiologia, Dept. de Biologia Cellular, de Fisiologia i d'Immunologia of UAB, especially Sheila Ons, for technical assistance in the immunocytochemistry procedure, and Gerald-Patrick Fannon, Ph.D., for revising the manuscript. These data were presented at the 36th Annual Meeting of the Society for Neuroscience (2004) and the 37th Annual General Meeting of the EBBS (2005).

\section{References}

Alvarez, P., Lipton, P.A., Melrose, R., and Eichenbaum, H. 2001. Differential effects of damage within the hippocampal region on memory for a natural, nonspatial Odor-Odor Association. Learn. Mem. 8: 79-86.

Amenta, F., Bronzetti, E., Caporali, M.G., Ciriaco, E., Germana, G.P., Niglio, T., Ricci, A., and de Carolis, A.S. 1991. Nucleus basalis magnocellularis lesions impair mossy fiber system in rat hippocampus: A quantitative histochemical and ultrastructural study. Arch. Gerontol. Geriatr. 12: 49-58.

Bailey, A.M., Rudisill, M.L., Hoof, E.J., and Loving, M.L. 2003. 192 IgG-saporin lesions to the nucleus basalis magnocellularis (nBM) disrupt acquisition of learning set formation. Brain Res. 969: 147159.

Bakin, J.S. and Weinberger, N.M. 1996. Induction of a physiological memory in the cerebral cortex by stimulation of the nucleus basalis. Proc. Natl. Acad. Sci. 93: 11219-11224.

Baxter, M.G. and Chiba, A.A. 1999. Cognitive functions of the basal forebrain. Curr. Opin. Neurobiol. 9: 178-183.

Baxter, M.G., Bucci, D.J., Holland, P.C., and Gallagher, M. 1999. Impairments in conditioned stimulus processing and conditioned responding after combined selective removal of hippocampal and neocortical cholinergic input. Behav. Neurosci. 113: 486-495.

Berger-Sweeney, J., Stearns, N.A., Frick, K.M., Beard, B., and Baxter, M.G. 2000. Cholinergic basal forebrain is critical for social transmission of food preferences. Hippocampus 10: 729-738.

Bjordahl, T.S., Dimyan, M.A., and Weinberger, N.M. 1998. Induction of long-term receptive field plasticity in the auditory cortex of the waking guinea pig by stimulation of the nucleus basalis. Behav. Neurosci. 112: 467-479.

Brightwell, J.J., Smith, C.A., Countryman, R.A., Neve, R.L., and Colombo, P.J. 2005. Hippocampal overexpression of mutant creb blocks long-term, but not short-term memory for a socially transmitted food preference. Learn. Mem. 12: 12-17.

Bringmann, A. and Klingberg, F. 1990. Behaviour-dependent changes of the acoustically evoked potential in the frontal cortex of the freely moving rat and modulation by electrical basal forebrain stimulation. Biomed. Biochim. Acta 49: 597-605.

Bunsey, M. and Eichenbaum, H. 1995. Selective damage to the hippocampal region blocks long-term retention of a natural and nonspatial stimulus-stimulus association. Hippocampus 5: 546-556.

Butt, A.E., Schultz, J.A., Arnold, L.L., Garman, E.E., George, C.L., and Garraghty, P.E. 2003. Lesions of the rat nucleus basalis magnocellularis disrupt appetitive-to-aversive transfer learning. Integr. Physiol. Behav. Sci. 38: 253-271.

Buzsaki, G., Bickford, R.G., Ponomareff, G., Thal, L.J., Mandel, R., and Gage, F.H. 1988. Nucleus basalis and thalamic control of neocortical activity in the freely moving rat. J. Neurosci. 8: 4007-4026.

Casamenti, F., Deffenu, G., Abbamondi, A.L., and Pepeu, G. 1986. Changes in cortical acetylcholine output induced by modulation of the nucleus basalis. Brain Res. Bull. 16: 689-695.

Chiba, A.A., Bucci, D.J., Holland, P.C., and Gallagher, M. 1995. Basal forebrain cholinergic lesions disrupt increments but not decrements in conditioned stimulus processing. J. Neurosci. 15: 7315-7322.

Chudasama, Y., Dalley, J.W., Nathwani, F., Bouger, P., and Robbins, T.W. 2004. Cholinergic modulation of visual attention and working memory: Dissociable effects of basal forebrain 192-IgG-saporin lesions and intraprefrontal infusions of scopolamine. Learn. Mem. 11: $78-86$.

Clark, R.E., Broadbent, N.J., Zola, S.M., and Squire, L.R. 2002. Anterograde amnesia and temporally graded retrograde amnesia for a nonspatial memory task after lesions of hippocampus and subiculum. J. Neurosci. 22: 4663-4669.

Conner, J.M., Culberson, A., Packowski, C., Chiba, A.A., and Tuszynski, M.H. 2003. Lesions of the Basal forebrain cholinergic system impair task acquisition and abolish cortical plasticity associated with motor skill learning. Neuron 38: 819-829.

Countryman, R.A., Kaban, N.L., and Colombo, P.J. 2005a. Hippocampal c-fos is necessary for long-term memory of a socially transmitted food preference. Neurobiol. Learn. Mem. 84: 175-183.

Countryman, R.A., Orlowski, J.D., Brightwell, J.J., Oskowitz, A.Z., and Colombo, P.J. 2005b. CREB phosphorylation and c-Fos expression in the hippocampus of rats during acquisition and recall of a socially transmitted food preference. Hippocampus 15: 56-67.

Dalley, J.W., Cardinal, R.N., and Robbins, T.W. 2004. Prefrontal executive and cognitive functions in rodents: Neural and neurochemical substrates. Neurosci. Biobehav. Rev. 28: 771-784.

Detari, L. 2000. Tonic and phasic influence of basal forebrain unit activity on the cortical EEG. Behav. Brain Res. 115: 159-170.

Dimyan, M.A. and Weinberger, N.M. 1999. Basal forebrain stimulation induces discriminative receptive field plasticity in the auditory 
cortex. Behav. Neurosci. 113: 691-702.

Duque, A., Balatoni, B., Detari, L., and Zaborszky, L. 2000. EEG correlation of the discharge properties of identified neurons in the basal forebrain. J. Neurophysiol. 84: 1627-1635.

Edeline, J.M., Hars, B., Maho, C., and Hennevin, E. 1994. Transient and prolonged facilitation of tone-evoked responses induced by basal orebrain stimulations in the rat auditory cortex. Exp. Brain Res. 97: $373-386$

Eichenbaum, H. 1999. The hippocampus and mechanisms of declarative memory. Behav. Brain Res. 103: 123-133.

Everitt, B.J. and Robbins, T.W. 1997. Central cholinergic systems and cognition. Annu. Rev. Psychol. 48: 649-684.

Galef Jr., B.G. and Wigmore, S.R. 1983. Transfer of information concerning distant foods: A laboratory investigation of the 'information-centre' hypothesis. Anim. Behav. 31: 748-758.

Galef Jr., B.G., Kennett, D.J., and Stein, M. 1985. Demonstrator influence on observer diet preference: Effects of simple exposure and the presence of a demonstrator. Anim. Learn. Behav. 13: 25-30.

Galef Jr., B.G., Mason, J.R., Preti, G., and Bean, N.J. 1988. Carbon disulfide: A semiochemical mediating socially-induced diet choice in rats. Physiol. Behav. 42: 119-124.

Gill, T.M., Sarter, M., and Givens, B. 2000. Sustained visual attention performance-associated prefrontal neuronal activity: Evidence for cholinergic modulation. J. Neurosci. 20: 4745-4757.

Gold, P.E. 2003. Acetylcholine modulation of neural systems involved in learning and memory. Neurobiol. Learn. Mem. 80: 194-210.

Golmayo, L., Nunez, A., and Zaborszky, L. 2003. Electrophysiological evidence for the existence of a posterior cortical-prefrontal-basal forebrain circuitry in modulating sensory responses in visual and somatosensory rat cortical areas. Neuroscience 119: 597-609.

Gritti, I., Manns, I.D., Mainville, L., and Jones, B.E. 2003. Parvalbumin, calbindin, or calretinin in cortically projecting and GABAergic, cholinergic, or glutamatergic basal forebrain neurons of the rat J. Comp. Neurol. 458: 11-31.

Hars, B., Maho, C., Edeline, J.M., and Hennevin, E. 1993. Basal forebrain stimulation facilitates tone-evoked responses in the auditory cortex of awake rat. Neuroscience 56: 61-74.

Herdegen, T. and Leah, J.D. 1998. Inducible and constitutive transcription factors in the mammalian nervous system: Control of gene expression by Jun, Fos and Krox, and CREB/ATF proteins. Brain Res. Brain Res. Rev. 28: 370-490.

Herrera, D.G. and Robertson, H.A. 1996. Activation of c-fos in the brain. Prog. Neurobiol. 50: 83-107.

Himmelheber, A.M., Sarter, M., and Bruno, J.P. 2001. The effects of manipulations of attentional demand on cortical acetylcholine release. Brain Res. Cogn. Brain Res. 12: 353-370.

Jimenez-Capdeville, M.E., Dykes, R.W., and Myasnikov, A.A. 1997. Differential control of cortical activity by the basal forebrain in rats: A role for both cholinergic and inhibitory influences. J. Comp. Neurol. 381: 53-67.

Johnston, M.V., McKinney, M., and Coyle, J.T. 1979. Evidence for a cholinergic projection to neocortex from neurons in basal forebrain. Proc. Natl. Acad. Sci. 76: 5392-5396.

Kilgard, M.P. and Merzenich, M.M. 1998. Cortical map reorganization enabled by nucleus basalis activity. Science 279: 1714-1718.

Kilgard, M.P., Pandya, P.K., Vazquez, J., Gehi, A., Schreiner, C.E., and Merzenich, M.M. 2001. Sensory input directs spatial and temporal plasticity in primary auditory cortex. J. Neurophysiol. 86: 326-338.

Kogan, J.H., Frankland, P.W., Blendy, J.A., Coblentz, J., Marowitz, Z., Schutz, G., and Silva, A.J. 1997. Spaced training induces normal long-term memory in CREB mutant mice. Curr. Biol. 7: 1-11.

Kurosawa, M., Sato, A., and Sato, Y. 1989. Stimulation of the nucleus basalis of Meynert increases acetylcholine release in the cerebral cortex in rats. Neurosci. Lett. 98: 45-50.

Langlais, P.J., Connor, D.J., and Thal, L. 1993. Comparison of the effects of single and combined neurotoxic lesions of the nucleus basalis magnocellularis and dorsal noradrenergic bundle on learning and memory in the rat. Behav. Brain Res. 54: 81-90.

Lehmann, J., Nagy, J.I., Atmadia, S., and Fibiger, H.C. 1980. The nucleus basalis magnocellularis: The origin of a cholinergic projection to the neocortex of the rat. Neuroscience 5: 1161-1174.

Lehmann, O., Grottick, A.J., Cassel, J.C., and Higgins, G.A. 2003. A double dissociation between serial reaction time and radial maze performance in rats subjected to 192 IgG-saporin lesions of the nucleus basalis and/or the septal region. Eur. J. Neurosci. 18: $651-666$.

Linster, C., Garcia, P.A., Hasselmo, M.E., and Baxter, M.G. 2001. Selective loss of cholinergic neurons projecting to the olfactory system increases perceptual generalization between similar, but not dissimilar, odorants. Behav. Neurosci. 115: 826-833.

Lipton, P.A., Alvarez, P., and Eichenbaum, H. 1999. Crossmodal associative memory representations in rodent orbitofrontal cortex.
Neuron 22: 349-359.

Manns, I.D., Alonso, A., and Jones, B.E. 2003. Rhythmically discharging basal forebrain units comprise cholinergic, GABAergic, and putative glutamatergic cells. J. Neurophysiol. 89: 1057-1066.

Mayeux-Portas, V., File, S.E., Stewart, C.L., and Morris, R.J. 2000. Mice lacking the cell adhesion molecule Thy- 1 fail to use socially transmitted cues to direct their choice of food. Curr. Biol. 10: 68-75.

McGaughy, J., Kaiser, T., and Sarter, M. 1996. Behavioral vigilance following infusions of 192 IgG-saporin into the basal forebrain: Selectivity of the behavioral impairment and relation to cortical AChE-positive fiber density. Behav. Neurosci. 110: 247-265.

McGaughy, J., Dalley, J.W., Morrison, C.H., Everitt, B.J., and Robbins, T.W. 2002. Selective behavioral and neurochemical effects of cholinergic lesions produced by intrabasalis infusions of 192 IgG-saporin on attentional performance in a five-choice serial reaction time task. J. Neurosci. 22: 1905-1913.

McKinney, M. and Jacksonville, M.C. 2005. Brain cholinergic vulnerability: relevance to behavior and disease. Biochem. Pharmacol. 70: $1115-1124$.

McLin III, D.E., Miasnikov, A.A., and Weinberger, N.M. 2002. The effects of electrical stimulation of the nucleus basalis on the electroencephalogram, heart rate, and respiration. Behav. Neurosci. 116: 795-806.

McLin III, D.E., Miasnikov, A.A., and Weinberger, N.M. 2003. CS-specific gamma, theta, and alpha EEG activity detected in stimulus generalization following induction of behavioral memory by stimulation of the nucleus basalis. Neurobiol. Learn. Mem. 79: 152-176.

Mercado, E., Bao, S., Orduna, I., Gluck, M.A., and Merzenich, M.M. 2001. Basal forebrain stimulation changes cortical sensitivities to complex sound. Neuroreport 12: 2283-2287.

Mesulam, M.M., Mufson, E.J., Wainer, B.H., and Levey, A.I. 1983. Central cholinergic pathways in the rat: An overview based on an alternative nomenclature (Ch1-Ch6). Neuroscience 10: 1185-1201.

Metherate, R. and Ashe, J.H. 1991. Basal forebrain stimulation modifies auditory cortex responsiveness by an action at muscarinic receptors. Brain Res. 559: 163-167.

Metherate, R., Cox, C.L., and Ashe, J.H. 1992. Cellular bases of neocortical activation: Modulation of neural oscillations by the nucleus basalis and endogenous acetylcholine. J. Neurosci. 12: $4701-4711$.

Miasnikov, A.A., McLin III, D., and Weinberger, N.M. 2001. Muscarinic dependence of nucleus basalis induced conditioned receptive field plasticity. Neuroreport 12: 1537-1542.

Miasnikov, A.A., Chen, J.C., and Weinberger, N.M. 2006. Rapid induction of specific associative behavioral memory by stimulation of the nucleus basalis in the rat. Neurobiol. Learn. Mem. 86: 47-65.

Montero-Pastor, A., Vale-Martinez, A., Guillazo-Blanch, G., Nadal-Alemany, R., Marti-Nicolovius, M., and Morgado-Bernal, I. 2001. Nucleus basalis magnocellularis electrical stimulation facilitates two-way active avoidance retention, in rats. Brain Res. 900: $337-341$

Montero-Pastor, A., Vale-Martinez, A., Guillazo-Blanch, G., and Marti-Nicolovius, M. 2004. Effects of electrical stimulation of the nucleus basalis on two-way active avoidance acquisition, retention, and retrieval. Behav. Brain Res. 154: 41-54.

Muir, J.L., Dunnett, S.B., Robbins, T.W., and Everitt, B.J. 1992. Attentional functions of the forebrain cholinergic systems: Effects of intraventricular hemicholinium, physostigmine, basal forebrain lesions and intracortical grafts on a multiple-choice serial reaction time task. Exp. Brain Res. 89: 611-622.

Otto, T. and Eichenbaum, H. 1992. Complementary roles of the orbital prefrontal cortex and the perirhinal-entorhinal cortices in an odor-guided delayed-nonmatching-to-sample task. Behav. Neurosci. 106: $762-775$

Pandya, P.K., Moucha, R., Engineer, N.D., Rathbun, D.L., Vazquez, J., and Kilgard, M.P. 2005. Asynchronous inputs alter excitability, spike timing, and topography in primary auditory cortex. Hear. Res. 203: $10-20$.

Panocka, I., Sagratella, S., Scotti de Carolis, A., Zeng, Y.C., and Amenta, F. 1995. Microanatomical and electrophysiological changes of the rat dentate gyrus caused by lesions of the nucleus basalis magnocellularis. Neurosci. Lett. 190: 207-211.

Paxinos, G. and Watson, C. 1997. The rat brain in stereotaxic coordinates. Elsevier, Amsterdam.

Quiroz-Padilla, M.F., Guillazo-Blanch, G., Vale-Martinez, A., and Marti-Nicolovius, M. 2006. Excitotoxic lesions of the parafascicular nucleus produce deficits in a socially transmitted food preference. Neurobiol. Learn. Mem. (in press).

Rampon, C., Tang, Y.P., Goodhouse, J., Shimizu, E., Kyin, M., and Tsien, J.Z. 2000. Enrichment induces structural changes and recovery from nonspatial memory deficits in CA1 NMDAR1-knockout mice. Nat. 
Neurosci. 3: 238-244.

Rasmusson, D.D. 2000. The role of acetylcholine in cortical synaptic plasticity. Behav. Brain Res. 115: 205-218.

Ridley, R.M., Baker, H.F., Leow-Dyke, A., and Cummings, R.M. 2005. Further analysis of the effects of immunotoxic lesions of the basal nucleus of Meynert reveals substantial impairment on visual discrimination learning in monkeys. Brain Res. Bull. 65: 433-442.

Robbins, T.W. 2002. The 5-choice serial reaction time task: Behavioural pharmacology and functional neurochemistry. Psychopharmacology 163: 362-380.

Roberts, M. and Shapiro, M. 2002. NMDA receptor antagonists impair memory for nonspatial, socially transmitted food preference. Behav. Neurosci. 116: 1059-1069.

Ross, R.S. and Eichenbaum, H. 2006. Dynamics of hippocampal and cortical activation during consolidation of a nonspatial memory. J. Neurosci. 26: 4852-4859.

Ross, R.S., McGaughy, J., and Eichenbaum, H. 2005. Acetylcholine in the orbitofrontal cortex is necessary for the acquisition of a socially transmitted food preference. Learn. Mem. 12: 302-306.

Roullet, F., Lienard, F., Datiche, F., and Cattarelli, M. 2005. Fos protein expression in olfactory-related brain areas after learning and after reactivation of a slowly acquired olfactory discrimination task in the rat. Learn. Mem. 12: 307-317.

Sabbatini, M., Bronzetti, E., Felici, L., Fringuelli, C., Sagratella, S., and Amenta, F. 1999. NADPH-diaphorase histochemistry in the rat cerebral cortex and hippocampus: Effect of electrolytic lesions of the nucleus basalis magnocellularis. Mech. Ageing Dev. 107: 147-157.

Saddoris, M.P., Gallagher, M., and Schoenbaum, G. 2005. Rapid associative encoding in basolateral amygdala depends on connections with orbitofrontal cortex. Neuron 46: 321-331.

Sarter, M. and Bruno, J.P. 2002. The neglected constituent of the basal forebrain corticopetal projection system: GABAergic projections. Eur. J. Neurosci. 15: 1867-1873.

Sarter, M., Givens, B., and Bruno, J.P. 2001. The cognitive neuroscience of sustained attention: Where top-down meets bottom-up. Brain Res. Brain Res. Rev. 35: 146-160.

Sarter, M., Bruno, J.P., and Givens, B. 2003. Attentional functions of cortical cholinergic inputs: What does it mean for learning and memory? Neurobiol. Learn. Mem. 80: 245-256.

Schoenbaum, G., Chiba, A.A., and Gallagher, M. 1998. Orbitofrontal cortex and basolateral amygdala encode expected outcomes during learning. Nat. Neurosci. 1: 155-159.

Semba, K. 2000. Multiple output pathways of the basal forebrain: Organization, chemical heterogeneity, and roles in vigilance. Behav. Brain Res. 115: 117-141.

Tronel, S. and Sara, S.J. 2002. Mapping of olfactory memory circuits: Region-specific c-fos activation after odor-reward associative learning or after its retrieval. Learn. Mem. 9: 105-111.

Turchi, J. and Sarter, M. 1997. Cortical acetylcholine and processing capacity: Effects of cortical cholinergic deafferentation on crossmodal divided attention in rats. Brain Res. Cogn. Brain Res. 6: 147-158.

Vale-Martinez, A., Baxter, M.G., and Eichenbaum, H. 2002. Selective lesions of basal forebrain cholinergic neurons produce anterograde and retrograde deficits in a social transmission of food preference task in rats. Eur. J. Neurosci. 16: 983-998.

Verdier, D. and Dykes, R.W. 2001. Long-term cholinergic enhancement of evoked potentials in rat hindlimb somatosensory cortex displays characteristics of long-term potentiation. Exp. Brain Res. 137: 71-82.

Waite, J.J., Wardlow, M.L., and Power, A.E. 1999. Deficit in selective and divided attention associated with cholinergic basal forebrain immunotoxic lesion produced by 192-saporin; motoric/sensory deficit associated with Purkinje cell immunotoxic lesion produced by OX7-saporin. Neurobiol. Learn. Mem. 71: 325-352.

Weinberger, N.M. 2003. The nucleus basalis and memory codes: Auditory cortical plasticity and the induction of specific, associative behavioral memory. Neurobiol. Learn. Mem. 80: 268-284.

Weinberger, N.M. 2004. Specific long-term memory traces in primary auditory cortex. Nat. Rev. Neurosci. 5: 279-290.

Wenk, G.L. 1997. The nucleus basalis magnocellularis cholinergic system: One hundred years of progress. Neurobiol. Learn. Mem. 67: 85-95.

Wenk, H., Bigl, V., and Meyer, U. 1980. Cholinergic projections from magnocellular nuclei of the basal forebrain to cortical areas in rats. Brain Res. 2: 295-316.

Wenk, G.L., Markowska, A.L., and Olton, D.S. 1989. Basal forebrain lesions and memory: Alterations in neurotensin, not acetylcholine, may cause amnesia. Behav. Neurosci. 103: 765-769.

Whishaw, I.Q., Tomie, J.A., and Kolb, B. 1992. Ventrolateral prefrontal cortex lesions in rats impair the acquisition and retention of a tactile-olfactory configural task. Behav. Neurosci. 106: 597-603.

Winocur, G. 1990. Anterograde and retrograde amnesia in rats with dorsal hippocampal or dorsomedial thalamic lesions. Behav. Brain Res. 38: 145-154.

Winocur, G. and Moscovitch, M. 1999. Anterograde and retrograde amnesia after lesions to frontal cortex in rats. J. Neurosci. 19: 96119617.

Winocur, G., McDonald, R.M., and Moscovitch, M. 2001. Anterograde and retrograde amnesia in rats with large hippocampal lesions. Hippocampus 11: 18-26.

Winters, B.D. and Bussey, T.J. 2005. Removal of cholinergic input to perirhinal cortex disrupts object recognition but not spatial working memory in the rat. Eur. J. Neurosci. 21: 2263-2270.

Wood, H. and de Belleroche, J. 1991. Induction of c-fos mRNA in cerebral cortex by excitotoxin stimulation of cortical inputs: Involvement of N-methyl-D-aspartate receptors. Brain Res. 545: 183-190.

Woolf, N.J., Eckenstein, F., and Butcher, L.L. 1983. Cholinergic projections from the basal forebrain to the frontal cortex: A combined fluorescent tracer and immunohistochemical analysis in the rat. Neurosci. Lett. 40: $93-98$.

Works, S.J., Wilson, R.E., and Wellman, C.L. 2004. Age-dependent effect of cholinergic lesion on dendritic morphology in rat frontal cortex. Neurobiol. Aging 25: 963-974.

Wrenn, C.C., Harris, A.P., Saavedra, M.C., and Crawley, J.N. 2003. Social transmission of food preference in mice: Methodology and application to galanin-overexpressing transgenic mice. Behav. Neurosci. 117: 21-31.

Zhang, Y., Hakes, J.J., Bonfield, S.P., and Yan, J. 2005. Corticofugal feedback for auditory midbrain plasticity elicited by tones and electrical stimulation of basal forebrain in mice. Eur. J. Neurosci. 22: $871-879$.

Received May 2, 2006; accepted in revised form July 21, 2006. 


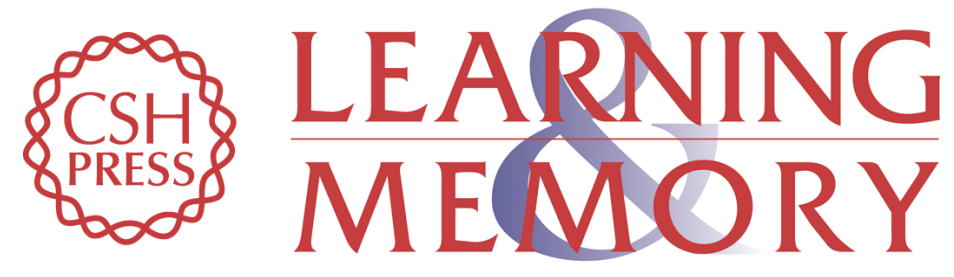

\section{Effects of nucleus basalis magnocellularis stimulation on a socially transmitted food preference and c-Fos expression}

Núria Boix-Trelis, Anna Vale-Martínez, Gemma Guillazo-Blanch, et al.

Learn. Mem. 2006, 13: originally published online November 13, 2006

Access the most recent version at doi:10.1101/lm.305306

References This article cites 102 articles, 17 of which can be accessed free at:

http://learnmem.cshlp.org/content/13/6/783.full.html\#ref-list-1

License

Email Alerting Receive free email alerts when new articles cite this article - sign up in the box at the Service top right corner of the article or click here. 